\title{
Rates of Quenching and Hydrogen Abstraction of Benzophenone Triplet with Cumene and Oligostyrenes
}

\author{
Kazuyuki HorIE, Toshie TAKAGI, Itaru MITA, \\ Yoichi SHINDO, ${ }^{*}$ Hisaya SATO, ${ }^{* *}$ \\ and Yasuyuki TANAKA** \\ Institute of Interdisciplinary Research, Faculty of Engineering, \\ University of Tokyo, 4-6-1 Komaba, Meguro-ku, Tokyo 153, Japan \\ *Department of Chemistry, Faculty of Science, Toho University, \\ Miyama, Funabashi-shi 274, Japan \\ **Department of Material Systems Engineering, Faculty of Technology, \\ Tokyo University of Agriculture and Technology, \\ Koganei-shi, Tokyo 184, Japan
}

(Received April 17, 1984)

\begin{abstract}
Rate constants of quenching, $k_{\mathrm{q}}$, and hydrogen abstraction, $k_{\mathrm{a}}$, of benzophenone triplet with oligostyrenes from dimer to hexamer as well as with cumene were determined in acetonitrile at $30^{\circ} \mathrm{C}$ from transient phosphorescence decay and quantum yield for benzophenone reduction measurements. The values of $k_{\mathrm{q}}=(4.0 \pm 1.0) \times 10^{6}$ unit- $^{-1} \mathrm{~s}^{-1}$ and $k_{\mathrm{a}}=(1.3 \pm 0.3) \times 10^{5}$ unit- $\mathrm{M}^{-1} \mathrm{~s}^{-1}$ for oligostyrenes are independent of the number of monomer unit, $n$. The $k_{\mathrm{q}}$ for oligostyrene is three times larger than $k_{\mathrm{q}}$ for cumene, its monomer model, supposingly due to a sandwich-type encounter of benzophenone with two adjacent phenyl groups, but $k_{\mathrm{a}}$ for oligostyrene is equal to $k_{\mathrm{a}}$ for cumene. The chemical reaction (hydrogen abstraction) contributes in only $3.5 \%$ to total deactivation of benzophenone triplet by oligostyrenes.
\end{abstract}

KEY WORDS Benzophenone / Triplet / Oligostyrene / Cumene / Hydrogen

Abstraction / Quenching / Rate Constant /

In the previous study of benzophenonesensitized photodegradation of polystyrene in benzene solution, ${ }^{1}$ we have found that the rate of benzophenone disappearance in benzene under $365 \mathrm{~nm}$ irradiation does not increase but decrease by the addition of polystyrene to the system, though the main-chain scission of polystyrene proceeds during the irradiation. The results together with transient measurements have suggested the importance of quenching of benzophenone triplet by polystyrene, the very small rate of direct hydrogen abstraction of benzophenone triplet from polystyrene, and the occurrence of successive hydrogen abstractions by triplet benzophenone from benzene and by phenyl radical from polystyrene.
The literature values for the rate constants of hydrogen abstraction, $k_{\mathrm{a}}$, and quenching, $k_{\mathrm{q}}$, of benzophenone triplet with cumene, a monomer model for polystyrene, show scatter $\left(k_{\mathrm{a}}=6 \times 10^{5}, 7 \times 10^{4}\right.$, or $3 \times 10^{4} \mathrm{M}^{-1} \mathrm{~s}^{-1},{ }^{2-4}$ and $k_{\mathrm{q}}=5 \times 10^{5}$ or $\left.3.7 \times 10^{6} \mathrm{M}^{-1} \mathrm{~s}^{-1}\right) .{ }^{5,6} \mathrm{In}$ the study of the reactivity of benzophenone triplet with aliphatic hydrocarbons by transient measurements, the discussion on $k_{\mathrm{a}}$ was given with the experimental values of $k_{\mathrm{q}}$ on the basis of the assumption of $k_{\mathrm{a}} \cong k_{\mathrm{q}}{ }^{7,8}$ This assumption, however, does not hold for the case of aromatic hydrocarbon, where rapid quenching of benzophenone triplet by aromatic rings occurs. ${ }^{9}$ The independent meaurements of $k_{\mathrm{q}}$ and $k_{\mathrm{a}}$ have been given recently for the reactions of benzophenone triplet with phe- 


\section{K. HORIE et al.}

nols, ${ }^{10}$ amines, ${ }^{11,12}$ olefins, ${ }^{13}$ and thiols. ${ }^{14}$

These situations prompted us to measure the rate constant for direct hydrogen abstraction of benzophenone triplet from polystyrene, and compare it with that of a model compound. In the present paper, rate constants for quenching and hydrogen abstraction reactions of benzophenone triplet with oligostyrenes from dimer to hexamer have been measured in acetonitrile at $30^{\circ} \mathrm{C}$ and are compared with the results with cumene and benzene.

\section{EXPERIMENTAL}

\section{Materials}

The styrene oligomers were prepared according to the following procedure. ${ }^{15,16}$ Styrene was anionically oligomerized with $n$ butyllithium in diethyl ether at $-20^{\circ} \mathrm{C}$ under argon atmosphere.

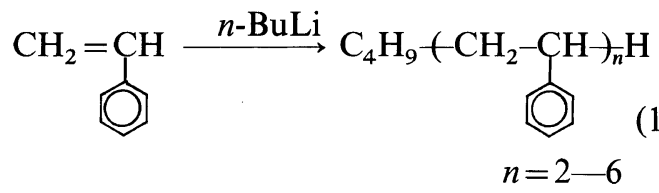

The resulting mixture of oligomers containing mainly dimer to hexamer was fractionated by gel permeation chromatography (GPC) by the use of a preparative column $(21.2 \mathrm{~mm}$ i.d. $\times 600 \mathrm{~mm}$ ) packed with a high resolution styrene-divinylbenzene gel using chloroform as an eluent. The purity of each oligomer determined with analytical GPC column was more than $95 \%$. Benzophenone was twice recrystallized from ethanol solution. Spectroscopic grade cumene and benzene were distilled, and Dotite-Spectrosol grade acetonitrile was twice distilled before use. Acetonitrile was used as an appropriate solvent which is inert to benzophenone triplet and dissolves oligostyrenes at room temperature, though it does not dissolve high-molecularweight polystyrene in the same condition.

\section{Photoirradiation Procedures}

A $450 \mathrm{~W}$ high-pressure mercury lamp
(Ushio UM-453B) with a combination of two pyrex glass cylinders and a glass filter (Toshiba UV-D36A) was used as a light source of $365 \mathrm{~nm}$. The sample solution in rectangular quartz cell with $1.0 \mathrm{~cm}$ light path length was degassed by several freeze-pump-thaw cycles under high vacuum and then sealed off. All photoirradiations were carried out in a thermostat maintained at $30^{\circ} \mathrm{C}$. Actinometry was carried out with an International Light IL$411 \mathrm{~T}$ type photoresist photometer calibrated by the potassium ferrioxalate/o-phenanthroline system. ${ }^{17}$ The incident intensity was about $2.8 \times 10^{-8}$ einstein $\mathrm{cm}^{-2} \mathrm{~s}^{-1}$ in the present experiments.

\section{Ultra-Violet Absorption Measurements}

Changes in benzophenone concentration in the sample solutions during photoirradiation were followed by the decrease in optical density for benzophenone $n-\pi^{*}$ absorption at $340 \mathrm{~nm}$ measured with a Shimadzu MP-5000 type spectrophotometer.

\section{Transient Measurements of Quenching Rate Constants}

A pulsed nitrogen laser (Avco C950B) as an exciting light at $337 \mathrm{~nm}$, thermostat, monochromator (Jasco CT10), photomultiplier (HTV R374), transient time converter (RikenDenshi TCG 8000) were used for measuring the lifetimes of benzophenone phosphorescence in the degassed sample solutions in acetonitrile and its quenching rate constants by oligostyrene. The apparatuses are almost same as those previously used for the triplet probe study of intermacromolecular reactions, ${ }^{18,19}$ and the details of the measurements have been given elsewhere. ${ }^{18,20}$

\section{Phosphorescence Intensity Measurements}

The phosphorescence spectra of benzophenone in the same sample solutions were measured with a Jasco FP-500 type spectrofluorometer at $25^{\circ} \mathrm{C}$ for an alternate estimation of quenching rate constants. 


\section{RESULTS AND DISCUSSION}

\section{Benzophenone Disappearance during Station- ary-State Irradiation}

Typical examples for the change in absorption spectra and its semilogarithmic plots for the optical density at $340 \mathrm{~nm}$ during the $365 \mathrm{~nm}$ light irradiation of benzophenone in acetonitrile at $30^{\circ} \mathrm{C}$ in the presence and absence of oligostyrene are shown in Figure 1. The absorption at $340 \mathrm{~nm}$ is due to $n-\pi^{*}$ transition of benzophenone $\left(\varepsilon=158 \quad \mathrm{M}^{-1}\right.$ $\mathrm{cm}^{-1}$ ), and the change in optical density at $340 \mathrm{~nm}$ was ascertained to correspond to the decrease of benzophenone concentration and the formation of benzopinacol by GPC measurements in a similar manner as described in the previous paper. ${ }^{1}$ The formation of benzopinacol is a proof of the occurrence of hydrogen abstraction by benzophenone triplet.

The first-order plots of benzophenone concentration, [BP], against time, $t$, gave straight lines with the slopes larger in the presence of oligostyrene than the slope without styrene oligomer, as are exemplified in Figure 1 (insert). The slopes can be related to the quantum yield for benzophenone disappearance, $\Phi_{(- \text {BP })}$, and various rate constants in the following manner.

The primary processes for the decay of benzophenone triplet $\left({ }^{3} \mathrm{BP}^{*}\right)$ in acetonitrile (AcCN) in the presence of polystyrene oligomer (PS) is expressed in eq $2-7$ by considering the presence of both physical quenching and hydrogen abstraction with polystyrene oligomer and solvent.

$$
\begin{aligned}
& \mathrm{BP} \stackrel{h v}{\longrightarrow}{ }^{1} \mathrm{BP}^{*} \longrightarrow{ }^{3} \mathrm{BP}^{*} \\
& { }^{3} \mathrm{BP} * \stackrel{k_{\mathrm{d}}}{\longrightarrow} \mathrm{BP} \quad \text { Deactivation } \\
& { }^{3} \mathrm{BP}^{*}+\mathrm{AcCN} \stackrel{k_{\mathrm{qd}}^{\mathrm{A}}}{\mathrm{BP}}+\mathrm{AcCN}
\end{aligned}
$$

Physical quenching

$$
{ }^{3} \mathrm{BP}^{*}+\mathrm{PS} \stackrel{k_{\mathrm{qd}}^{\mathrm{PS}}}{\mathrm{BP}}+\mathrm{PS}
$$

Physical quenching

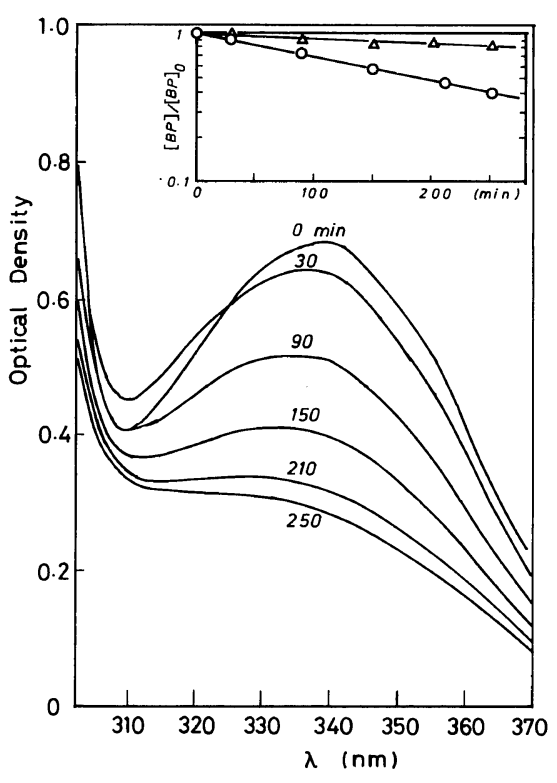

Figure 1. Change in UV spectra during photoirradiation of benzophenone $\left(4.3 \times 10^{-3} \mathrm{M}\right)$ with styrene dimer $\left(1.8 \times 10^{-2}\right.$ unit-M $)$ in acetonitrile at $30^{\circ} \mathrm{C}$ and its first-order plots (insert). $O$, in the presence of styrene dimer; $\triangle$, without styrene oligomer.

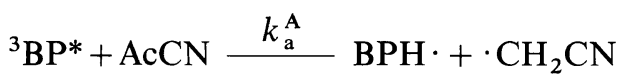

Quenching by $\mathrm{H}$-abstraction

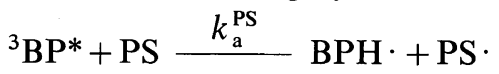

Quenching by $\mathrm{H}$-abstraction

where $k_{\mathrm{d}}=k_{\mathrm{PT}}+k_{\mathrm{IT}}$ includes the phosphorescence process $\left(k_{\mathrm{PT}}\right)$ and non-radiative deactivation $\left(k_{\mathrm{IT}}\right)$. The rate of disappearance of benzophenone under the photostationary state is expressed by

$$
\begin{aligned}
& -\mathrm{d}[\mathrm{BP}] / \mathrm{d} t=\left(k_{\mathrm{a}}^{\mathrm{A}}[\mathrm{AcCN}]+k_{\mathrm{a}}^{\mathrm{PS}}[\mathrm{PS}]\right)\left[{ }^{3} \mathrm{BP} \mathrm{P}^{*}\right] \\
& =\frac{\left(k_{\mathrm{a}}^{\mathrm{A}}[\mathrm{AcCN}]+k_{\mathrm{a}}^{\mathrm{PS}}[\mathrm{PS}]\right) \times 10^{3} I_{0}\left(1-10^{-\varepsilon[\mathrm{BP}] l}\right) / l}{k_{\mathrm{d}}+\left(k_{\mathrm{a}}^{\mathrm{A}}+k_{\mathrm{qd}}^{\mathrm{A}}\right)[\mathrm{AcCN}]+\left(k_{\mathrm{a}}^{\mathrm{PS}}+k_{\mathrm{qd}}^{\mathrm{PS}}\right)[\mathrm{PS}]} \\
& \cong \Phi_{(-\mathrm{BP})} \times 2.3 \times 10^{3} I_{0} \varepsilon f[\mathrm{BP}]
\end{aligned}
$$

where the quantum yield of benzophenone disappearance, $\Phi_{(-\mathrm{BP})}$, is given by

$$
\begin{aligned}
& \Phi_{(-\mathrm{BP})} \\
& =\frac{k_{\mathrm{a}}^{\mathrm{A}}[\mathrm{AcCN}]+k_{\mathrm{a}}^{\mathrm{PS}}[\mathrm{PS}]}{k_{\mathrm{d}}+\left(k_{\mathrm{a}}^{\mathbf{A}}+k_{\mathrm{q} d}^{\mathbf{A}}[\mathrm{AcCN}]+\left(k_{\mathrm{a}}^{\mathrm{PS}}+k_{\mathrm{qd}}^{\mathrm{PS}}\right)[\mathrm{PS}]\right.}
\end{aligned}
$$


$I_{0}$ is the intensity of incident light in einstein $\mathrm{cm}^{-2} \mathrm{~s}^{-1}, \varepsilon$ the molar extinction coefficient of benzophenone in $\mathrm{M}^{-1} \mathrm{~cm}^{-1}, f=\left(1-10^{-\varepsilon[\mathrm{BP}] l}\right) /$ $(2.3 \varepsilon[\mathrm{BP}] l)$ the correction factor for the absorbed dose with optical pass of $l \mathrm{~cm}$. Equation 8 can be transformed to eq 10 , corresponding to the first-order plot of benzophenone concentration, $[\mathrm{BP}]$, against time, $t$, during the photoirradiation,

$$
\begin{aligned}
\ln \left([\mathrm{BP}] /[\mathrm{BP}]_{0}\right) & =-2.3 \times 10^{3} \Phi_{(-\mathrm{BP})} I_{0} \varepsilon f t \\
& =-K t
\end{aligned}
$$

where $[\mathrm{BP}]_{0}$ is the initial benzophenone concentration and $K$ is the slope for the first-order plot. The change in $f$ during irradiation is negligible compared with the accuracy of the present experimental data, and the value of $f$ for $[\mathrm{BP}]=[\mathrm{BP}]_{0}$ and $l=1 \mathrm{~cm}$ were used in the calculation. The values of $\Phi_{(- \text {BP })}$ were thus determined from the slopes $K$ of the experimental first-order plots by using eq 10 .

\section{Decay of Benzophenone Phosphorescence}

The lifetime, $\tau$, of benzophenone triplet in acetonitrile and its quenching rate constant, $k_{\mathrm{q}}^{\mathrm{PS}}=k_{\mathrm{qd}}^{\mathrm{PS}}+k_{\mathrm{a}}^{\mathrm{PS}}$, by styrene oligomer were obtained from the transient measurements of phosphorescence decays at $450 \mathrm{~nm}$ of sample solutions excited by nitrogen laser pulse at $337 \mathrm{~nm}$. The concentration of triplet-state benzophenone $\left[{ }^{3} \mathrm{BP}^{*}\right]$ in the case of pulse irradiation is given by

$$
\begin{aligned}
{\left[{ }^{3} \mathrm{BP} *\right]=\left[{ }^{3} \mathrm{BP}^{*}\right]_{0} \exp \left\{-\left(k_{\mathrm{d}}+k_{\mathrm{q}}^{\mathrm{A}}[\mathrm{AcCN}]\right.\right.} \\
\left.\left.+k_{\mathrm{q}}^{\mathrm{PS}}[\mathrm{PS}]\right) t\right\} \\
=\left[{ }^{3} \mathrm{BP}^{*}\right]_{0} \exp (-t / \tau)
\end{aligned}
$$

where $k_{\mathrm{q}}^{\mathrm{A}}=k_{\mathrm{qd}}^{\mathrm{A}}+k_{\mathrm{a}}^{\mathrm{A}}$. As the transient phosphorescence intensity $I(t)$ at time $t$ after pulse irradiation is proportional to $k_{\mathrm{PT}}\left[{ }^{3} \mathrm{BP} *\right]$, the logarithmic decay of $I(t)$ gives straight line with the slope equal to reciprocal lifetime $1 / \tau$.

$$
\begin{aligned}
\ln I(t) & =-\left(k_{\mathrm{d}}+k_{\mathrm{q}}^{\mathrm{A}}[\mathrm{AcCN}]+k_{\mathrm{q}}^{\mathrm{PS}}[\mathrm{PS}]\right) t \\
& =-(1 / \tau) t
\end{aligned}
$$

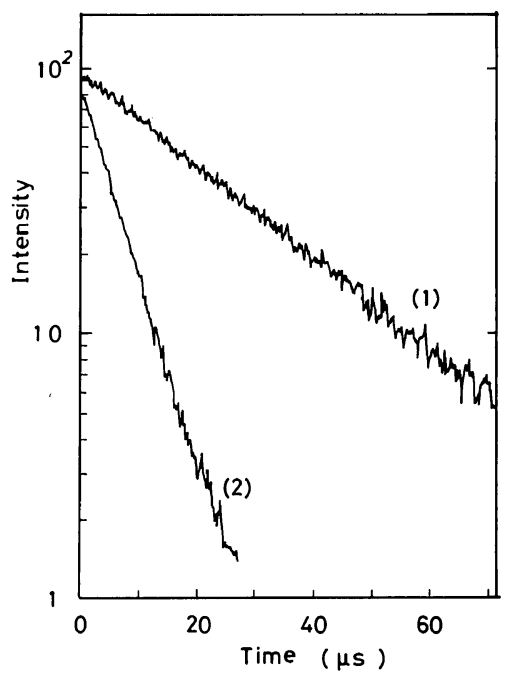

Figure 2. Logarithmic decay of benzophenone phosphorescence at $450 \mathrm{~nm}$ in acetonitrile at $30^{\circ} \mathrm{C}$ after $10 \mathrm{~ns}$ pulse excitation with nitrogen laser. $[\mathrm{BP}]_{0}=$ $4.3 \times 10^{-3} \mathrm{M}$. (1) without styrene oligomer, (2) in the presence of styrene dimer $\left(2.5 \times 10^{-2}\right.$ unit-M).

Typical semilogarithmic decay curves of transient benzophenone phosphorescence are shown in Figure 2. The values of $k_{\mathrm{q}}^{\mathrm{PS}}$ were calculated from the slopes of these straight lines and eq 13,

$$
\begin{aligned}
1 / \tau & =k_{\mathrm{d}}+k_{\mathrm{q}}^{\mathrm{A}}[\mathrm{AcCN}]+k_{\mathrm{q}}^{\mathrm{PS}}[\mathrm{PS}] \\
& =1 / \tau_{0}+k_{\mathrm{q}}^{\mathrm{PS}}[\mathrm{PS}]
\end{aligned}
$$

where $1 / \tau_{0}=k_{\mathrm{d}}+k_{\mathrm{q}}^{\mathrm{A}}[\mathrm{AcCN}]$ is the reciprocal lifetime in the absence of oligostyrene. The lifetime of benzophenone triplet, $\tau_{0}$, in acetonitrile at $30^{\circ} \mathrm{C}$ was $35 \mu \mathrm{s}$ in the present experiments. The difference from the literature value $\left(\tau_{0}=104 \mu \mathrm{s}\right)^{7}$ may be due to a trace of oxygen or impurity remaining in the solvent, but it does not disturb the determination of $k_{\mathrm{q}}$. The rate of spontaneous deactivation, $k_{\mathrm{d}}$, of benzophenone triplet in non-viscous solution at ambient temperature is supposedly much smaller than $1 / \tau_{0}$, and the value of $k_{\mathrm{d}}=$ $1.4 \times 10^{3} \mathrm{~s}^{-1}$ is reported in perfluoromethylcyclohexane at $20^{\circ} \mathrm{C}^{21}$ The value of $k_{\mathrm{q}}^{\mathrm{PS}}$ can also be determined from the stationary-state phosphorescence intensity, $I$, of the samples at 
Rates of Quenching and Hydrogen Abstraction of Benzophenone Triplet

Table I. Quantum yields for benzophenone disappearance, $\Phi_{(-\mathrm{BP})}$, rate constants for quenching, $k_{\mathrm{q}}$, and for hydrogen abstraction, $k_{\mathrm{a}}$, of benzophenone triplet with oligostyrenes and related compounds in acetonitrile at $30^{\circ} \mathrm{C}$

\begin{tabular}{lcccc}
\hline Oligostyrene & $\begin{array}{c}{[\mathrm{PS}]^{\mathrm{a}}} \\
(\text { unit-M) }\end{array}$ & $\Phi_{(-\mathrm{BP})}$ & $\begin{array}{c}k_{\mathrm{q}}^{\mathrm{b}} \\
\left(\text { unit-M }^{-1} \mathrm{~s}^{-1}\right)\end{array}$ & $\begin{array}{c}k_{\mathrm{a}} \\
\text { (unit-M }\end{array}$ \\
\hline Dimer & $\left.1.8 \times 10^{-2} \mathrm{~s}^{-1}\right)$ \\
Trimer & $9.5 \times 10^{-3}$ & $3.2 \times 10^{-2}$ & $3.8 \times 10^{6}$ & $1.6 \times 10^{5}$ \\
Tetramer & $1.7 \times 10^{-2}$ & $3.1 \times 10^{-2}$ & $2.9 \times 10^{6}$ & $1.6 \times 10^{5}$ \\
Pentamer & $2.4 \times 10^{-3}$ & $1.1 \times 10^{-2}$ & $2.9 \times 10^{6}$ & $1.3 \times 10^{5}$ \\
Hexamer & $1.0 \times 10^{-2}$ & $1.8 \times 10^{-2}$ & $5.5 \times 10^{6}$ & $1.0 \times 10^{5}$ \\
Cumene & $1.0 \times 10^{-2}$ & $3.0 \times 10^{-2}$ & $3.9 \times 10^{6}$ & $1.0 \times 10^{5}$ \\
Benzene & 11.0 (bulk) & $9.3 \times 10^{-3}$ & $1.2 \times 10^{6}$ & $1.0 \times 10^{5}$ \\
Acetonitrile & 19.1 (bulk) & $7.7 \times 10^{-3}$ & $1.5 \times 10^{4}$ & $1.4 \times 10^{2}$ \\
\hline
\end{tabular}

a Oligostyrene concentration for $\Phi_{(-\mathrm{BP})}$ measurements.

b Obtained from transient measurements.

c $[\mathrm{BP}]_{0}=(4-6) \times 10^{-3} \mathrm{M}$.

$450 \mathrm{~nm}$ measured with spectrofluorometer together with the value of $\tau_{0}$ by using SternVolmer relationship ${ }^{5}$

$$
I_{0} / I=1+k_{\mathrm{q}}^{\mathrm{PS}} \tau_{0}[\mathrm{PS}]
$$

where $I_{0}$ is the stationary-state phosphorescence intensity of the sample without oligostyrene.

\section{Rate Constants for Hydrogen Abstraction and Quenching}

By introducing the value of $\Phi_{(-\mathrm{BP})}$ and $\tau_{0}$ in the absence of oligostyrene into eq 9 , we get $k_{\mathrm{a}}^{\mathrm{A}}[\mathrm{AcCN}]=2.2 \times 10^{2} \mathrm{~s}^{-1}$, and hence $k_{\mathrm{a}}^{\mathrm{A}}=12$ $\mathrm{M}^{-1} \mathrm{~s}^{-1}$ at $30^{\circ} \mathrm{C}$ with $[\mathrm{AcCN}]=19.1 \mathrm{M}$. The rate constants for hydrogen abstraction of benzophenone triplet from oligostyrene, $k_{\mathrm{a}}^{\mathrm{PS}}$, were then calculated from eq 9 by using the corresponding values of $\Phi_{(-\mathrm{BP})}$, [PS], and $k_{\mathrm{q}}^{\mathrm{PS}}$ together with the value of $\tau_{0}$ and $k_{\mathrm{a}}^{\mathrm{A}}[\mathrm{AcCN}]$. The results are summarized in Table $I$ as well as the values for cumene and benzene. The values of $k_{\mathrm{q}}^{\mathbf{P S}}$ and $k_{\mathrm{a}}^{\mathbf{P S}}$ are illustrated in Figure 3 against the number of monomer units, $n$, in oligostyrenes. The plots for $n=1$ correspond to cumene. It should be noted that $\Phi_{(-\mathrm{BP})}$ for oligostyrene is the function of oligostyrene concentration [PS], as is expressed in eq 9. But it would become constant $\left(\Phi_{(-\mathrm{BP})} \cong k_{\mathrm{a}}^{\mathrm{PS}} / k_{\mathrm{q}}^{\mathrm{PS}}\right)$

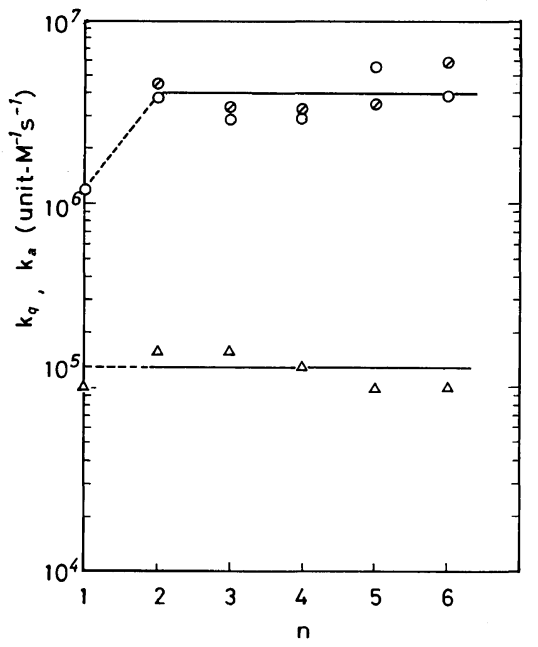

Figure 3. Rate constants for quenching, $k_{\mathrm{q}}^{\mathrm{PS}},(\bigcirc, \oslash)$ and for hydrogen abstraction, $k_{\mathrm{a}}^{\mathrm{PS}},(\triangle)$ of benzophenone triplet with oligostyrenes of $n$ monomer units in acetonitrile at $30^{\circ} \mathrm{C}$. The values for $n=1$ correspond to cumene. $\bigcirc$, from transient measurements; $\oslash$, from phosphorescence intensity measurements.

for the condition of $k_{\mathrm{q}}^{\mathrm{PS}}[\mathrm{PS}] \gg 1 / \tau_{0}$ and $k_{\mathrm{a}}^{\mathrm{PS}}[\mathrm{PS}] \gg k_{\mathrm{a}}^{\mathrm{A}}[\mathrm{AcCN}]$.

The values of $k_{\mathbf{q}}^{\mathrm{PS}}$ are almost constant with the average value of $(4.0 \pm 1.0) \times 10^{6}$ unit- $\mathrm{M}^{-1}$ $\mathrm{s}^{-1}$ for oligostyrenes from dimer to hexamer. The transient measurements with nitrogen laser pulse and the stationary-state measure- 


\section{K. HORIE et al.}

ments with spectrofluorometer gave the same results within the range of experimental error. This value of $k_{\mathbf{q}}^{\mathbf{P S}}$ is about three times larger than $k_{\mathrm{q}}$ for cumene and more than hundred times larger than $k_{\mathrm{q}}$ for benzene. A similar tendency has been observed for the quenching of 9-methylanthracene triplet by polystyrene. ${ }^{22}$ The value of $k_{\mathrm{q}}^{\mathrm{PS}}$ for benzene agrees with that reported $\left(1.3 \times 10^{4} \mathrm{M}^{-1} \mathrm{~s}^{-1}\right.$ in trichlorotrifluoroethane). ${ }^{9}$ As the change in electron density of the phenyl group has been supposed to affect much on its quenching rate of benzophenone triplet, ${ }^{9}$ the difference of $k_{\mathrm{q}}^{\mathrm{PS}}$ from $k_{\mathrm{q}}$ for cumene and benzene can be attributed to the electrodonating ability of the substituents in oligostyrenes and cumene. The difference of $k_{\mathrm{q}}^{\mathrm{PS}}$ from $k_{\mathrm{q}}$ for cumene might also be due to the cooperative effect of adjacent phenyl rings in oligostyrenes which might hold benzophenone between them providing a sandwichtype encounter pair conformation. The comparison of the present results for oligostyrenes with the values of $k_{\mathrm{q}}^{\mathrm{PS}}$ for high-molecularweight polystyrene in benzene $\left(k_{\mathrm{q}}^{\mathrm{PS}}=1.2 \times 10^{6}\right.$ unit- $\mathrm{M}^{-1} \mathrm{~s}^{-1}$ at $30^{\circ} \mathrm{C}^{1}$ and $1.9 \times 10^{6}$ unit$\left.\mathrm{M}^{-1} \mathrm{~s}^{-1}\right)^{6}$ reveals that there is no severe molecular weight dependence for quenching of benzophenone triplet by polystyrene in accord with the supposition ${ }^{8,23}$ for non-diffusioncontrolled reactions between polymer and a small molecule.

The rate constants for hydrogen abstraction, $k_{\mathrm{a}}^{\mathrm{PS}}$, are also constant for oligostyrenes from dimer to hexamer, and the average value of $k_{\mathrm{a}}^{\mathrm{PS}}=(1.3 \pm 0.3) \times 10^{5}$ unit- $\mathrm{M}^{-1} \mathrm{~s}^{-1}$ is equal to $k_{\mathrm{a}}$ for cumene, model compound for styrene monomer unit. The value of $k_{\mathrm{a}}$ for benzene agrees well with that reported $\left(1.6 \times 10^{2}\right.$ $\left.\mathrm{M}^{-1} \mathrm{~s}^{-1}\right){ }^{24}$ For cases of non-diffusioncontrolled reactions, the rates for reactions between a polymer and a small molecule are usually considered to be equal to the rate for corresponding model reaction between small molecules. ${ }^{8,23,25}$ But for the hydrogen abstractions of tert-butoxy radical from polystyrene and polypropyrene, ${ }^{26,27}$ the molecular weight effects have been reported. The present case has ascertained that the abstraction rate of tertiary hydrogen by benzophenone triplet from oligostyrene main chain is independent of the number of repeating units when the rate constant is expressed in $1 \cdot$ unit- $\mathrm{mol}^{-1} \mathrm{~s}^{-1}$. The reason of reported very slow rates of hydrogen abstraction from polystyrene in benzene solution by benzophenone triplet ${ }^{1}$ and by tertbutoxy radical ${ }^{26}$ is not yet clarified, but it might be attributed to some complexity of the mechanism in benzene solution, for example, the possibility of backward disproportionation reaction that masks the actual yield of primary photoproducts.

Finally it should be noted that the deactivation of benzophenone triplet by oligostyrene and cumene in acetonitrile occurs mainly through quenching process by phenyl rings, and only $3.5 \%$ or $8.3 \%$ of deactivation is caused by the chemical reaction, i.e., hydrogen abstraction for tertiary hydrogen atom in oligostyrene or cumene, respectively.

\section{REFERENCES}

1. I. Mita, T. Takagi, K. Horie, and Y. Shindo, Macromolecules, 17, (11) (1984), in press.

2. J. C. Scaiano, J. Photochem., 2, 81 (1973/74).

3. G. S. Hammond, W. P. Baker, and W. M. Moore, $J$. Am. Chem. Soc., 83, 2795 (1961).

4. C. Walling and M. J. Gibian, J. Am. Chem. Soc., 87, 3361 (1965).

5. N. J. Turro, "Modern Molecular Photochemistry," Benjamin, Menlo Park, California, 1978, p 362.

6. A. F. Olea, M. V. Encinas, and E. A. Lissi, Macromolecules, 15, 1111 (1982).

7. L. Giering, M. Berger, and C. Steel, J. Am. Chem. Soc., 96, 953 (1974).

8. M. A. Winnik and V. Maharaj, Macromolecules, 12, 902 (1979).

9. M. W. Wolf, R. E. Brown, and L. A. Singer, J. Am. Chem. Soc., 99, 526 (1977).

10. P. K. Das, M. V. Ensinas, and J. C. Scaiano, J. Am. Chem. Soc., 103, 4154 (1981).

11. S. Inbar, H. Linschitz, and S. G. Cohen, J. Am. Chem. Soc., 102, 1419 (1980); 103, 1048 (1981).

12. D. Griller, J. A. Howard, P. R. Marriott, and J. C. Scaiano, J. Am. Chem. Soc., 103, 619 (1981).

13. M. V. Encinas and J. C. Scaiano, J. Am. Chem. Soc., 103, 6393 (1981). 
Rates of Quenching and Hydrogen Abstraction of Benzophenone Triplet

14. S. Inbar, H. Linschitz, and S. G. Cohen, J. Am. Chem. Soc., 104, 1679 (1982).

15. H. Sato, K. Saito, K. Miyashita, and Y. Tanaka, Makromol. Chem., 182, 2259 (1981).

16. H. Sato, Y. Tanaka, and K. Hatada, Makromol. Chem., Rapid Commun., 3, 175 (1982).

17. S. L. Murov, "Handbook of Photochemistry," Marcel Dekker, New York, 1973, p 119.

18. K. Horie and I. Mita, Polym. J., 9, 201 (1977).

19. K. Horie and I. Mita, Macromolecules, 111175 (1978); I. Mita, K. Horie, and M. Takeda, ibid., 14, 1428 (1981); I. Mita, K. Horie, and M. Masuda, Polym. Bull., 4, 369 (1981).

20. K. Horie, K. Morishita, and I. Mita, Kobunshi Ronbunshu, 40, 217 (1983).
21. C. A. Parker, and T. A. Joyce, Trans. Faraday Soc., 65, 2823 (1969).

22. H. Ushiki, K. Horie, A. Okamoto, and I. Mita, Polym. J., 11, 691 (1979).

23. I. Mita and K. Horie, "Degradation and Stabilization of Polymers," Vol. 1, H. H. G. Jellinek, ed., Elsevier, Amsterdam, 1983, p 235.

24. A. V. Buettner and J. Dedinas, J. Phys. Chem., 75, 187 (1971).

25. A. Okamoto, Y. Shimanuki, and I. Mita, Eur. Polym. J., 18, 545 (1982).

26. E. Niki and Y. Kamiya, J. Org. Chem., 38, 1403 (1973).

27. E. Niki and Y. Kamiya, J. Chem. Soc., Perkin Trans. 2, 1221 (1975). 